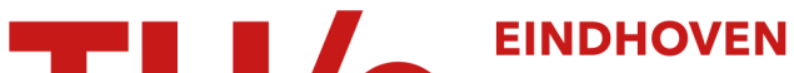 \\ UNIVERSITY OF \\ TECHNOLOGY
}

\section{Sound-driven fluid dynamics in pressurized carbon dioxide}

Citation for published version (APA):

lersel, van, M. M., Mettin, R., Benes, N. E., Schwarzer, D., \& Keurentjes, J. T. F. (2010). Sound-driven fluid dynamics in pressurized carbon dioxide. Journal of Chemical Physics, 133(4), 044304-1/4. [044304]. https://doi.org/10.1063/1.3463444

DOI:

10.1063/1.3463444

Document status and date:

Published: 01/01/2010

\section{Document Version:}

Publisher's PDF, also known as Version of Record (includes final page, issue and volume numbers)

\section{Please check the document version of this publication:}

- A submitted manuscript is the version of the article upon submission and before peer-review. There can be important differences between the submitted version and the official published version of record. People interested in the research are advised to contact the author for the final version of the publication, or visit the $\mathrm{DOI}$ to the publisher's website.

- The final author version and the galley proof are versions of the publication after peer review.

- The final published version features the final layout of the paper including the volume, issue and page numbers.

Link to publication

\section{General rights}

Copyright and moral rights for the publications made accessible in the public portal are retained by the authors and/or other copyright owners and it is a condition of accessing publications that users recognise and abide by the legal requirements associated with these rights.

- Users may download and print one copy of any publication from the public portal for the purpose of private study or research.

- You may not further distribute the material or use it for any profit-making activity or commercial gain

- You may freely distribute the URL identifying the publication in the public portal.

If the publication is distributed under the terms of Article 25fa of the Dutch Copyright Act, indicated by the "Taverne" license above, please follow below link for the End User Agreement:

www.tue.nl/taverne

Take down policy

If you believe that this document breaches copyright please contact us at:

openaccess@tue.nl

providing details and we will investigate your claim. 


\section{AIP Chemicalial Physics}

\section{Sound-driven fluid dynamics in pressurized carbon dioxide}

Maikel M. van lersel, Robert Mettin, Nieck E. Benes, Dirk Schwarzer, and Jos T. F. Keurentjes

Citation: J. Chem. Phys. 133, 044304 (2010); doi: 10.1063/1.3463444

View online: http://dx.doi.org/10.1063/1.3463444

View Table of Contents: http://jcp.aip.org/resource/1/JCPSA6/v133/i4

Published by the American Institute of Physics.

\section{Related Articles}

Acoustic properties of air-saturated porous materials containing dead-end porosity J. Appl. Phys. 110, 094903 (2011)

Note: Measurement method for sound velocity of melts in large volume press and its application to liquid sodium up to $2.0 \mathrm{GPa}$

Rev. Sci. Instrum. 82, 086108 (2011)

Dispersion and attenuation on the Brillouin sound waves of a lubricant: Di(2-ethylhexyl) sebacate under high pressures

J. Appl. Phys. 110, 033538 (2011)

Sound dispersion and attenuation in concentrated $\mathrm{H} 2 \mathrm{SO} 4$ by visible and ultraviolet Brillouin spectroscopy

J. Chem. Phys. 135, 034503 (2011)

Sub-wavelength phononic crystal liquid sensor

J. Appl. Phys. 110, 026101 (2011)

\section{Additional information on J. Chem. Phys.}

Journal Homepage: http://jcp.aip.org/

Journal Information: http://jcp.aip.org/about/about_the_journal

Top downloads: http://jcp.aip.org/features/most_downloaded

Information for Authors: http://jcp.aip.org/authors

\section{ADVERTISEMENT}

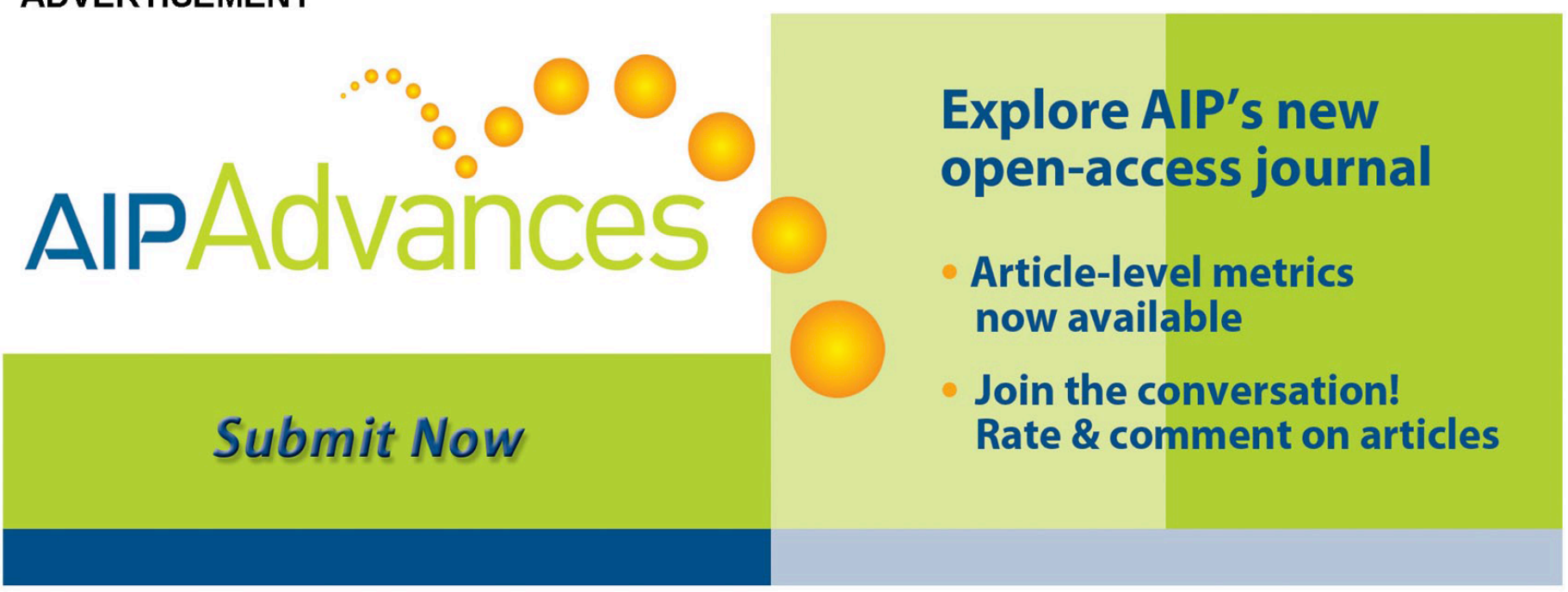




\title{
Sound-driven fluid dynamics in pressurized carbon dioxide
}

\author{
Maikel M. van lersel, ${ }^{1}$ Robert Mettin, ${ }^{2}$ Nieck E. Benes, ${ }^{3, a)}$ Dirk Schwarzer, ${ }^{4}$ and \\ Jos T. F. Keurentjes ${ }^{1}$ \\ ${ }^{1}$ Department of Chemical Engineering and Chemistry, Eindhoven University of Technology, \\ P.O. Box 513, $5600 \mathrm{MB}$ Eindhoven, The Netherlands \\ ${ }^{2}$ Drittes Physikalisches Institut, Universität Göttingen, Friedrich-Hund-Platz 1, 37077 Göttingen, Germany \\ ${ }^{3}$ Membrane Technology Group, Faculty of Science and Technology, Institute of Mechanics, \\ Processes and Control Twente (IMPACT), University of Twente, 7500 AE Enschede, The Netherlands \\ ${ }^{4}$ Max-Planck-Institut für Biophysikalische Chemie, Am Faßberg 11, 37077 Göttingen, Germany
}

(Received 10 December 2009; accepted 22 June 2010; published online 23 July 2010)

\begin{abstract}
Using high-speed visualization we demonstrate that ultrasound irradiation of pressurized carbon dioxide $\left(\mathrm{CO}_{2}\right)$ induces phenomena that do not occur in ordinary liquids at ambient conditions. For a near-critical mixture of $\mathrm{CO}_{2}$ and argon, sonication leads to extremely fast local phase separation, in which the system enters and leaves the two-phase region with the frequency of the imposed sound field. This phase transition can propagate with the speed of sound, but can also be located at fixed positions in the case of a standing sound wave. Sonication of a vapor-liquid interface creates a fine dispersion of liquid and vapor, irrespective whether the ultrasound horn is placed in the liquid or the vapor phase. In the absence of an interface, sonication of the liquid leads to ejection of a macroscopic vapor phase from the ultrasound horn with a velocity of several meters per second in the direction of wave propagation. The findings reported here potentially provide a tunable and noninvasive means for enhancing mass and heat transfer in high-pressure fluids. (C) 2010 American Institute of Physics. [doi:10.1063/1.3463444]
\end{abstract}

\section{INTRODUCTION}

High-pressure carbon dioxide $\left(\mathrm{CO}_{2}\right)$ is generally regarded as an environmentally benign alternative for organic solvents. ${ }^{1-3} \mathrm{CO}_{2}$ is nontoxic, nonflammable, and chemically inert and has the generally regarded as safe status. Its physicochemical properties are distinct and relatively easily tunable with small variations in pressure and temperature. Accordingly, $\mathrm{CO}_{2}$ is considered to be an interesting alternative to conventional solvents for a wide variety of applications, such as hydroformylation and polymerization reactions. Despite of the relatively high mass diffusivity in such lowviscous fluids, homogenization is complex and intense forms of mixing are desired. Ultrasound irradiation is known to provide a powerful tool to enhance mass transfer and several studies have explored the benefit of sonication for highpressure $\mathrm{CO}_{2}$ systems. The majority of these studies have focused on the extraction of active components, in which ultrasound led to significant improvements in extraction rate. ${ }^{4-9}$

The origin of this acceleration has been studied abundantly for water and organic solvents at ambient conditions. ${ }^{10-12}$ In these systems sonication results in the formation of liquid motion in the direction of wave propagation, i.e., acoustic streaming and acoustic cavitation. Acoustic cavitation refers to the sound-induced growth and nonlinear collapse of microscopic cavities in a liquid, leading to hotspots in the liquid. In the hot-spots, temperatures of several thousands of Kelvins, pressures of hundreds of bars, and high heating and cooling rates can be obtained. The extreme

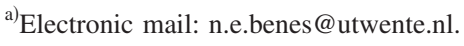

conditions can lead to the dissociation of chemical bonds and the formation of radicals. In addition, the collapsing cavities can induce high liquid velocities and microjets, thereby providing significant improvements in mass transfer.

Although it has been reported that ultrasound irradiation enhances mass transfer in high-pressure $\mathrm{CO}_{2}$-systems, it is still unclear to what extent this acceleration can be attributed to the occurrence of acoustic cavitation and streaming effects. Recent numerical modeling work has demonstrated that nonlinear cavity dynamics in high-pressure $\mathrm{CO}_{2}$ appears improbable. ${ }^{13}$ The present work elaborates on this numerical study and investigates the governing processes upon sonication of pressurized $\mathrm{CO}_{2}$ by means of high-speed visualization techniques.

\section{EXPERIMENTAL METHODS}

High-intensity ultrasound with a frequency of $20 \mathrm{kHz}$ was produced using an ultrasonic generator (Sonics and Materials VC750, Newtown, CT, USA). The piezoelectric transducer was coupled to the fluid with a $13 \mathrm{~mm}$ diameter full wave titanium alloy horn. The horn was inserted at the top of the reactor and positioned such that the tip of the horn was visible from the viewing area (Fig. 1). The reactor was equipped with two sapphire windows (diameter of $\sim 30 \mathrm{~mm}$ ) and had a volume of approximately $40 \mathrm{ml}$. To control temperature the reactor was immersed in a reservoir containing cooling liquid and the temperature of this liquid was controlled using cooling coils, which were connected to an external thermostat. The reactor was removed from the reservoir for the experiments in which the reactor was turned upside down or at an angle. High-speed images were re- 


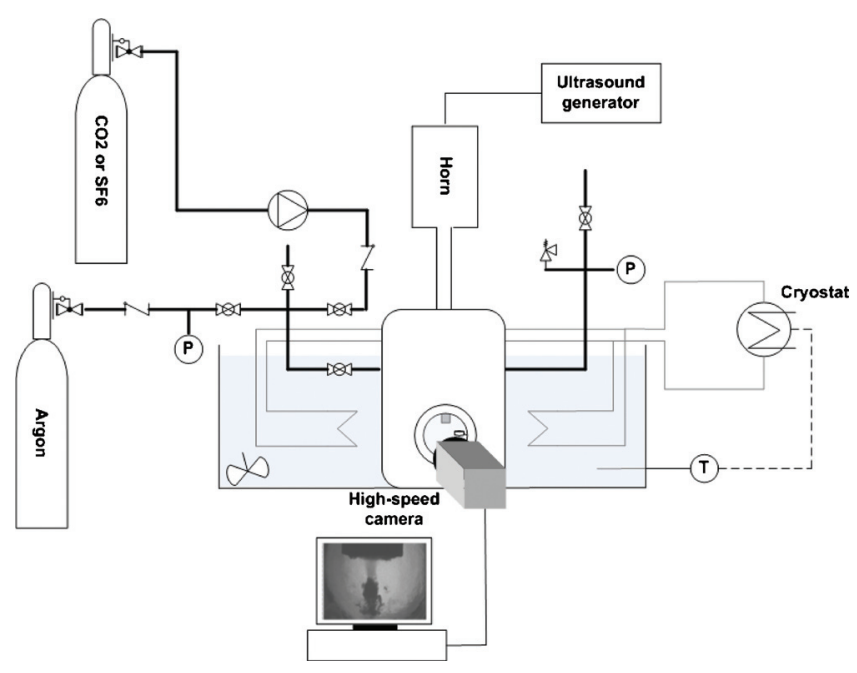

FIG. 1. Experimental setup for high-speed visualization experiments.

corded with a charge coupled device camera (Ultima APXRS, Photron USA, Inc., San Diego, CA, USA or MotionPro X4, Redlake MASD, Inc., San Diego, CA, USA) and magnifying optics, such as zoom lenses and a long-distance microscope. The contents of the reactor were visualized by background illumination using a slide projector.

First, the temperature of the cooling liquid in the reservoir was set by adjusting the temperature of the external thermostat. The reactor was flushed several times with gaseous $\mathrm{CO}_{2}$ (grade 4.5, Linde Gas B.V., Schiedam, The Netherlands) to remove any air present and filled with liquid $\mathrm{CO}_{2}$ using a syringe pump (LC-5000, Teledyne Isco, Inc., Lincoln, NE, USA). Subsequently, the hydrostatic pressure was set to the desired value by applying an argon head pressure (grade 5.0, Linde Gas B.V., Schiedam, The Netherlands). After thermal and pressure equilibrations, ultrasound was applied to the fluid and high-speed images were recorded. Since the mixture turned turbid almost instantaneously, images were captured during the first seconds of sonication.

\section{RESULTS AND DISCUSSION}

Recent numerical modeling work has revealed that for a mixture of $\mathrm{CO}_{2}$ and argon both mass and heat transport limitations impede cavity expansion and hence, nonlinear cavity motion. ${ }^{13}$ In accordance with this work, high-speed images acquired during the sonication of a similar mixture confirm that the cavities display hardly any radial motion. Although the experimental conditions have been varied extensively, nonlinearly oscillating cavities cannot be resolved from these images, thereby suggesting that acoustic cavitation does not occur in pressurized $\mathrm{CO}_{2}$. However, other phenomena appear upon sonication that are absent in ordinary liquids at ambient conditions. Similar to the physicochemical properties of this high-pressure fluid, the extent and time scales of the observed processes strongly depend on the position in the phase diagram (Fig. 2).

In the vicinity of the critical point (CP) (Fig. 2) local phase separation has been observed during each consecutive acoustic cycle, which implies that the system enters and leaves the two-phase region with a frequency equal to the

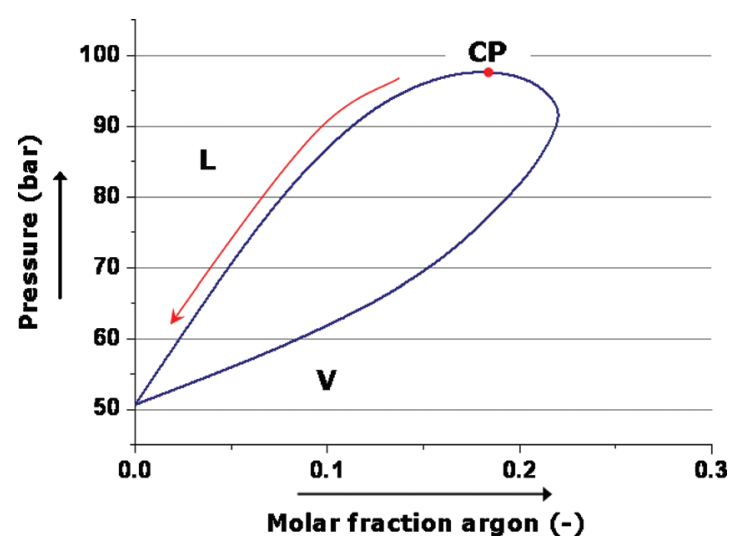

FIG. 2. Phase diagram for the binary system $\mathrm{CO}_{2}$-argon showing the composition of coexisting phases at $288 \mathrm{~K}$ (Refs. 14 and 15). The region above the bubble point curve corresponds to a single-phase liquid state, whereas below the dew point curve the system exists as a single-phase vapor. Mixtures with a composition located within the phase envelope will phase split into a liquid and a vapor. The dew and bubble point curves intersect at the CP. Above the critical point the distinction between vapor and liquid disappears and the fluid is in a supercritical state.

frequency of the imposed sound field [Fig. 3(a)]. Experiments confirm that this process exclusively arises in the vicinity of the critical point, which can be shifted for the binary mixture by changing temperature. The extremely fast dynamics of phase separation can be attributed to the unique physicochemical properties around the critical point, where most of the thermodynamic and transport properties diverge or converge to zero. ${ }^{16}$ In particular, the heat of evaporation and the surface tension approach zero and hence, the change in the Gibbs free energy required for phase separation is minute. The location of phase separation is determined by the spatial distribution of the sound field. For a traveling sound wave phase separation arises directly below the ultrasound horn and propagates in the direction of the wave with a velocity comparable to the speed of sound $(\sim 500 \mathrm{~m} / \mathrm{s})$, indicating that phase change occurs instantaneously in the negative pressure region of the sound wave. Propagation with the speed of sound suggests a strong resemblance with the well-studied piston effect in near-critical fluids, which refers to thermally induced acoustic waves responsible for

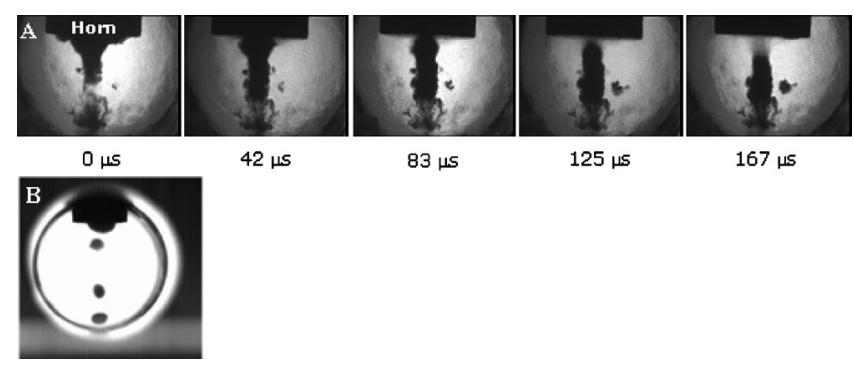

FIG. 3. High-speed images demonstrating the rapid dynamics of phase separation in the vicinity of the critical point of the mixture (side view). Upon sonication, the locations of phase separation depend on the spatial distribution of the sound field. (a) For a traveling sound wave phase separation arises directly below the horn and propagates in the direction of the wave with a velocity equal to the speed of sound at these conditions $(\sim 500 \mathrm{~m} / \mathrm{s})$. (b) In the presence of a standing wave phase separation occurs at the pressure antinodes. The image was recorded at a low frame rate (500 frames/s) to visualize all the locations of phase separation. 


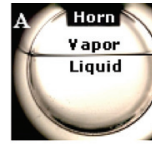

$0 \mathrm{~ms}$

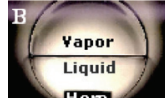

$0 \mathrm{~ms}$

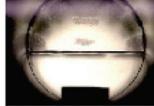

$2 \mathrm{~ms}$

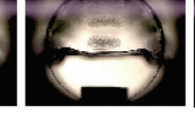

$5 \mathrm{~ms}$

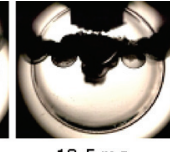

$13.5 \mathrm{~ms}$ $54 \mathrm{~ms}$

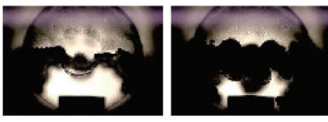

$21 \mathrm{~ms}$
FIG. 4. A sequence of high-speed images showing the ultrasound-induced disruption of the vapor-liquid interface, in which the first image corresponds to the start of sonication. Ultrasound with an intensity of $11 \mathrm{~W} / \mathrm{cm}^{2}$ was provided (a) from the top at $288 \mathrm{~K}$ and 52.5 bars and (b) from the bottom at $295 \mathrm{~K}$ and 57.5 bars. The darker regions in the vapor phase apparent from (b) imply the formation of a standing wave.

enhanced thermalization. ${ }^{17,18}$ In contrast to the piston effect, the frequency and acoustic pressure allow for direct manipulation of the time scale and the extent of phase separation. The tunability is also manifested by the possibility to induce phase separation at fixed positions in the sound field, i.e., at the pressure antinodes of a standing wave [Fig. 3(b)].

By lowering the hydrostatic pressure the mixture leaves the single-phase supercritical state, allowing the stable coexistence of a liquid and vapor phase. Sonication of the interface between liquid and vapor results in a vigorous interfacial disruption, leading to a dispersion of liquid and vapor [Fig. 4(a)]. Similar interfacial disruptions have been observed irrespective of liquid height and orientation and location of the ultrasound source [Fig. 4(b)]. Due to a difference in acoustic impedance of vapor and liquid, the sound wave induces a Langevin radiation force directed toward the phase with the lowest acoustic energy density, i.e., the liquid. ${ }^{19}$ The periodicity of the darker regions in the vapor phase in Fig. 4(b) reveals that a standing wave pattern can arise, thereby reinforcing the difference in acoustic energy density across the interface.

Although sonication of an interface in ambient systems can lead to disruption of the interface, the interfacial process presented here differs with respect to the extent of turbidity, the possibility to induce interfacial disruption by sonicating the vapor phase, and the interface wavelength. The difference in interfacial response is attributed to the low surface tension, high vapor density, and low liquid density of this high-pressure fluid. ${ }^{16}$ Studies on low-frequency mechanical agitation of near-critical $\mathrm{CO}_{2}$ have confirmed the special role of surface tension and density in the dynamics of the interfacial response. ${ }^{20-22}$ In Fig. 4 the observed interface wavelength is in the order of $1 \mathrm{~cm}$, a value approximately three orders of magnitude larger as compared to sonication in ambient systems. For ambient systems ultrasound irradiation leads to the Faraday excitation, which is characterized by waves of a few micrometers only. ${ }^{23}$ Magnified images of the interface reveal that waves of a few micrometers are superimposed on the waves shown in Fig. 4. This superposition would explain the strong correlation between predictions based on the Faraday instability and the droplet size as measured in the ultrasound-assisted emulsification of nearcritical $\mathrm{CO}_{2}$-water mixtures. ${ }^{24}$

When the liquid-vapor interface is located outside the

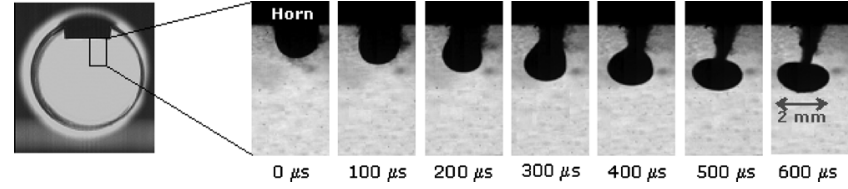

FIG. 5. A series of high-speed images showing the detachment of a macroscopic vapor phase. The vapor-liquid interface is located outside the reactor ( $288 \mathrm{~K}$ and 52.5 bars) and sonication results in the formation of an interface at the tip of the horn. Upon sonication the vapor phase expands and detaches with a velocity of $1.5 \mathrm{~m} / \mathrm{s}$ at an ultrasound intensity of $11 \mathrm{~W} / \mathrm{cm}^{2}$. The vapor phase appears dark against the bright background, which can be ascribed to surface waves arising from the interaction with the sound field (Ref. 27)

reactor, interface disruption is irrelevant and the repeated formation and high-velocity detachment of a macroscopic vapor phase become visible upon sonication of the liquid (Fig. 5). Typically, formation and detachment occur during a number of acoustic cycles $(\sim 10-500)$. Such a formation of a vapor phase (approximately in millimeters) is generally not observed for ambient systems, where sonication results in a cloud of oscillating cavities (approximately in micrometers). ${ }^{25,26}$

The negative pressure from the sound wave causes the vapor phase to form and to expand until at a critical radius necking occurs. In the final stage of necking the vapor phase accelerates and detaches with a velocity of several meters per second. The observed acceleration is faster for increasing acoustic pressure. In Fig. 5 acceleration is directed against the field of gravity. Experiments in which the reactor was placed at various angles with respect to gravity confirmed that detachment always occurs in the direction of the sound field. The formation and acceleration of a vapor phase were not observed when the horn was replaced by a heating rod with similar geometry and power dissipation, indicating that the forces deriving from the sound field are crucial for the high-velocity detachment process. It is well known that dispersed particles in a traveling sound wave experience an acoustic radiation force in the direction of wave propagation. ${ }^{28}$ As the size of the vapor phase and the wavelength of the sound field are of the same order of magnitude, the acoustic pressure gradient across the vapor phase gives rise to an additional force. The total force calculated for the detaching vapor phase is in good agreement with the acceleration estimated from the images depicted in Fig. 5. In these fluids drag and buoyancy forces are less pronounced due to the relatively low dynamic viscosity and small density difference between vapor and liquid, respectively.

By means of comparison, ultrasound irradiation of a mixture of sulfur hexafluoride and argon resulted in similar phenomena, demonstrating the generality of the observed phenomena with respect to the sonication of high-pressure fluids. In contrast to ordinary liquids, the practical implications of ultrasound irradiation for high-pressure fluids do not derive from acoustic cavitation. The observed ultrafast phase separation and vigorous interfacial response provide a tunable and noninvasive means for enhancing mass and heat transfer in high-pressure fluids, without undesired effects originating from radical formation. These implications are of 
interest for high-pressure liquid/liquid biphasic systems, gasexpanded solvents, and high-pressure reaction and extraction media.

\section{CONCLUSIONS}

This work demonstrates that ultrasound irradiation of high-pressure fluids leads to interesting phenomena that do not appear in water and organic solvents at ambient conditions. These phenomena allow for a substantial improvement of mass and heat transfer in high-pressure fluids. In the vicinity of the critical point sonication creates an extremely fast and local phase separation, which propagates through the mixture with a velocity equal to the speed of sound. Ultrasound irradiation of a vapor-liquid interface induces turbulent mixing of vapor and liquid, whereas in the absence of an interface a vapor phase is formed and ejected from the ultrasound source with a velocity of several meters per second. Similar phenomena have been observed for the sonication of pressurized sulfur hexafluoride, thereby demonstrating that these processes can be extended to other high-pressure fluids.

${ }^{1}$ P. G. Jessop and W. Leitner, Chemical Synthesis Using Supercritical Fluids (Wiley-VCH, Weinheim, 1999).

${ }^{2}$ E. J. Beckman, J. Supercrit. Fluids 28, 121 (2004).

${ }^{3}$ M. F. Kemmere and T. Meyer, Supercritical Carbon Dioxide (WileyVCH, Weinheim, 2005)

${ }^{4}$ J.-Z. Yin, D. Zhou, M.-S. Bi, L.-Y. Jia, and A.-Q. Wang, Chem. Eng. Commun. 196, 1322 (2009).

${ }^{5}$ Y. Gao, B. Nagy, X. Liu, B. Simándi, and Q. Wang, J. Supercrit. Fluids 49, 345 (2009)

${ }^{6}$ D. Luo, T. Qiu, and Q. Lu, J. Sci. Food. Agric. 87, 431 (2007).

${ }^{7}$ A.-J. Hu, S. Zhao, H. Liang, T.-Q. Qiu, and G. Chen, Ultrason. Sonochem. 14, 219 (2007).
${ }^{8}$ S. Balachandran, S. E. Kentish, R. Mawson, and M. Ashokkumar, Ultrason. Sonochem. 13, 471 (2006).

${ }^{9}$ E. Riera, Y. Golás, A. Blanco, J. A. Gallego, M. Blasco, and A. Mulet, Ultrason. Sonochem. 11, 241 (2004).

${ }^{10}$ K. S. Suslick, Science 247, 1439 (1990).

${ }^{11}$ M. P. Brenner, S. Hilgenfeldt, and D. Lohse, Rev. Mod. Phys. 74, 425 (2002).

${ }^{12}$ T. G. Leighton, The Acoustic Bubble (Academic, London, 1994).

${ }^{13}$ M. M. van Iersel, J. Cornel, N. E. Benes, and J. T. F. Keurentjes, J. Chem. Phys. 126, 064508 (2007).

${ }^{14}$ M. A. Mc Hugh and V. J. Krukonis, Supercritical Fluid Extraction (Butterworth-Heinemann, Boston, 1994).

${ }^{15}$ E. Sarashina and Y. S. Arai, J. Chem. Eng. Jpn. 4, 379 (1971).

${ }^{16}$ NIST Chemistry WebBook, edited by P. J. Lindstrom and W. G. Mallard (National Institute of Standards and Technology, Gaithersburg, MD, 2005), NIST Standard Reference Database No. 69.

${ }^{17}$ A. Onuki, H. Hao, and R. A. Ferrell, Phys. Rev. A 41, 2256 (1990).

${ }^{18}$ Y. Miura, S. Yoshihara, M. Ohnishi, K. Honda, M. Matsumoto, J. Kawai, M. Ishikawa, H. Kobayashi, and A. Onuki, Phys. Rev. E 74, 010101 (2006).

${ }^{19}$ B. T. Chu and R. E. Apfel, J. Acoust. Soc. Am. 72, 1673 (1982).

${ }^{20}$ S. Fauve, K. Kumar, C. Laroche, D. Beysens, and Y. Garrabos, Phys. Rev. Lett. 68, 3160 (1992).

${ }^{21}$ R. Wunenburger, P. Evesque, C. Chabot, Y. Garrabos, S. Fauve, and D. Beysens, Phys. Rev. E 59, 5440 (1999).

${ }^{22}$ W. González-Viñas and J. Salán, Europhys. Lett. 26, 665 (1994).

${ }^{23}$ J. Xu and D. Attinger, Phys. Fluids 19, 108107 (2007).

${ }^{24}$ M. T. Timko, K. A. Smith, R. L. Danheiser, J. I. Steinfeld, and J. W. Tester, AIChE J. 52, 1127 (2006).

${ }^{25}$ M. M. van Iersel, J.-P. A. J. van den Manacker, N. E. Benes, and J. T. F. Keurentjes, J. Phys. Chem. B 111, 3081 (2007).

${ }^{26} \mathrm{R}$. Mettin, in Bubble and Particle Dynamics in Acoustic Fields: Modern Trends and Applications, edited by A. A. Doinikov (Research Signpost, Kerala, 2005), pp. 1-38.

${ }^{27}$ R. G. Holt and E. H. Trinh, Phys. Rev. Lett. 77, 1274 (1996).

${ }^{28}$ A. A. Doinikov, in Bubble and Particle Dynamics in Acoustic Fields: Modern Trends and Applications, edited by A. A. Doinikov (Research Signpost, Kerala, 2005), pp. 39-67. 